\title{
Prevalence of Metabolic Obesity Normal Weight (MONW) in Cardiovascular Disease Patients - A Hospital-Based Case Control Study
}

\author{
Mayank Garg'1, Sandip Mohale ${ }^{2}$ \\ ${ }^{1}$ Department of Medicine, Jawaharlal Nehru Medical College, Wardha, Maharashtra, India. ${ }^{2}$ Department of \\ Medicine, Jawaharlal Nehru Medical College, Wardha, Maharashtra, India.
}

\section{ABSTRACT}

\section{BACKGROUND}

The risk of cardiovascular disease increases with obesity and thereby leads to increase in mortality in obese persons. Excess of adipose tissue causes cardiovascular abnormalities through endothelial dysfunction and insulin resistance. We wanted to study different risk factors for cardiovascular diseases by evaluating anthropometric measurements and lipid profiles in metabolic obese normal weight subjects with cardiovascular diseases.

\section{METHODS}

This case control study was conducted in Jawaharlal Nehru Medical College, AVBRH Hospital, Wardha. After taking clearance from the Institutional Ethical Committee, 200 cases with cardiovascular disease, and 200 controls without the cardiovascular disease, were selected and their lipid profile and anthropometric measurements were evaluated and compared gender wise.

\section{RESULTS}

There was significant association of weight in females $(56.81 \pm 3.94)$, BMI in males $(24.32 \pm 0.65)$, cholesterol in females $(177.72 \pm 16.93)$, height $(163.15 \pm 10.94$ in males and $154.81 \pm 3.76$ in females), lean mass (48.92 \pm 7.22 in males and $37.05 \pm$ 7.14 in females), \% body fat (22.79 \pm 7.23 in males and $35.04 \pm 9.73$ in females), waist circumference (102.93 \pm 1.12 in males and $93 \pm 0$ in females), Serum HDL (30.12 \pm 6.98 in males and $33.45 \pm 8.34$ in females), triglyceride (156.84 \pm 7.28 in males and $161.45 \pm 10.34$ in females) in both males and females. Whereas weight in males, BMI in females, cholesterol in males and serum LDL in both male and female had a P-value of greater than 0.05 and shows no possible association of these factors in the MONW subjects as a cause of cardiovascular diseases.

\section{CONCLUSIONS}

In this study, we found that there is a significant association between some factors of anthropometric measurements and lipid profile with MONW. Hence, it was concluded that an early screening will help in identifying persons with high risk of cardiovascular disease, and can be a major contributor in prevention of cardiovascular disease.

\section{KEY WORDS}

Cardiovascular Disease, Metabolic Obesity Normal Weight (MONW)
Corresponding Author:

Dr. Sandip Mohale,

Near Shitlamata Mandir,

$P$ and T Colony,

Sai Nagar, Wardha,

Maharashtra, India

E-mail: sandipmohale@yahoo.com

DOI: $10.14260 / j e m d s / 2020 / 528$

How to Cite This Article:

Garg M, Mohale S. Prevalence of metabolic obesity normal weight (MONW) in cardiovascular disease patients- a hospitalbased case control study. J Evolution Med Dent Sci 2020;9(34):2427-2431, DOI: $10.14260 / j e m d s / 2020 / 528$

Submission 27-04-2020,

Peer Review 11-07-2020,

Acceptance 17-07-2020,

Published 24-08-2020.

Copyright (c) 2020 JEMDS. This is an open access article distributed under Creative Commons Attribution License [Attribution 4.0 International (CC BY 4.0)] 


\section{BACKGROUND}

With the turn of the century, cardiovascular diseases (CVDs) have become the leading cause of mortality in India.[1] In comparison with the people of European ancestry, CVD affects Indians at least a decade earlier and in their most productive midlife years. ${ }^{[2,3]}$ For example, in Western populations only $23 \%$ of CVD deaths occur before the age of 70 years; in India, this number is $52 \% .{ }^{[4]}$ In addition, case fatality attributable to CVD in low-income countries, including India, appears to be much higher than in middle- and high-income countries.[5,6] The World Health Organization (WHO) has estimated that, with the current burden of CVD, India would lose $\$ 237$ billion from the loss of productivity and spending on health care over a 10-year period (2005-2015).[7] Nearly two-thirds of the burden of NCD mortality in India is currently contributed by CVD-related conditions. ${ }^{[8]}$ Cardiovascular disease is a broad term for a number of linked pathologies like coronary heart diseases, arrhythmias, peripheral arterial diseases, venous thromboembolism and rheumatic and congenital heart diseases. Cardiovascular disease is a significant and consistent problem in the world, leading to significant morbidity. In the countries people changes their lifestyle in such a ways that makes them obese and more prone to cardiovascular diseases increasing the burden on the countries productivity and health sectors. This burden can only be reduce by decreasing the risk factors for cardiovascular diseases in patients that is we have to adopt primary prevention approach in our health sectors. Risk factor includes weight, height, BMI, waist circumference, lean mass, \%body fat, LDL, HDL, triglyceride and cholesterol.

Metabolic obese normal weight (MONW) refers to people with normal weight and body mass index (BMI), who display some metabolic characteristics which increase the risk of developing metabolic syndrome in the same way. With the turn of the century, there is increase in cardiovascular mortality in the persons having normal weight obesity. An excess of the adipose tissue in the body may cause cardiovascular abnormalities as is associated with many comorbidities and pathophysiological processes like lipid metabolism, endothelial dysfunction, and insulin resistance. Clinicians and epidemiologists usually rely on body mass index (BMI) as a means of defining the presence of adiposity. In addition, central obesity is measured by increase in waist circumference (WC) or waist-to-hip ratio (WHR).[9] Increased weight and waist circumference have been shown to be strongly associated with cardiovascular disease risk factors such as diabetes and hypertension in many populations [10-12] that shows anthropometric measurements are related to the adiposity of the body. But now metabolic obese normal weight comes as a new effective way of screening for risk of cardiovascular diseases in population. If we use Metabolic obese normal weight along with lipid profile and anthropometric measurements, it not only strength our screening but also decrease cardiovascular disease proportion, its prevalence and the mortality cause by these diseases. These measurements can help to maintain the health better by individuals.

\section{Objectives}

1. To estimate different measurements that acts as the risk factors for cardiovascular diseases by doing anthropometric measurements and lipid profile in metabolic obese normal weight subjects with cardiovascular diseases.

2. To compare gender-wise the anthropometric measurements including BMI, waist circumference in cases of MONW with CVD to healthy non-obese control.

3. To correlate gender-wise the laboratory measurements including lean mass, triglyceride, serum LDL, serum HDL, total cholesterol in cases of MONW to healthy non-obese control.

\section{METHODS}

This is a case control study conducted over a period of six months. Patients admitted to medicine department of AVBRH with normal BMI and cardiovascular disease having abnormal ECG following 3 criteria for metabolic obesity normal weight (cases) were compared with patients with normal BMI without cardiovascular disease (controls).

\section{Inclusion Criteria}

For cases

1.BMI less than $25 \mathrm{Kg} / \mathrm{m}^{2}$

2.Age should be under greater than 20 to less than 60 years. 3.Patient satisfying three criteria of metabolic syndrome in case.

For controls

1.BMI less than $25 \mathrm{Kg} / \mathrm{m}^{2}$

2.Age should be under greater than 20 to less than 60 years. 3.Patient satisfying less than three criteria of metabolic syndrome in controls.

\section{Exclusion Criteria}

1. Individuals having BMI greater than $25 \mathrm{Kg} / \mathrm{m}^{2}$.

2. Individuals with age $>60$ years.

\section{Sample Size}

Sample size was estimated using formula

$\mathrm{n}=\mathrm{Z}^{2} \mathrm{pq} / \mathrm{e}^{2}$

where,

$\mathrm{n}=$ sample size

$\mathrm{Z}^{2}=$ abscissa of the normal curve that cuts off an area $\alpha$ at the tails ( 1 - $\alpha$ equals the desired confidence level, e.g., 95\%). The value for $\mathrm{Z}$ is found in statistical tables which contain the area under the normal curve and for 95\% confidence level it is 1.96 $\mathrm{e}=$ desired level of precision

$\mathrm{p}=$ estimated proportion of an attribute that is present in the population

$q=1-p$

Assume $\mathrm{p}=0.5$ (maximum variability) and supposing a desire confidence level of $95 \%$ and $\pm 5 \%$ precision the resulting sample size is 
$n=\frac{(1.96)^{2}(.5)(.5)}{(.05)^{2}}=385$

Sample size was determined to be 400 . We divide this sample size in to two equal halves in between cases and controls.

\section{Criteria for MONW}

The updated ATP-III definition of MONW [13] was met when three or more of the following criteria were present:

1. waist circumference $\geq 102 \mathrm{~cm}$ in men and $\geq 88 \mathrm{~cm}$ in women

2. $\mathrm{HDL}<1.04 \mathrm{mmol} / \mathrm{L}(40 \mathrm{mg} / \mathrm{dL})$ in men and $<1.30 \mathrm{mmol} / \mathrm{L}$ $(50 \mathrm{mg} / \mathrm{dL})$ in women

3. triglycerides $\geq 1.7 \mathrm{mmol} / \mathrm{L}(150 \mathrm{mg} / \mathrm{dL})$ or specific treatment for this lipid abnormality

4. systolic blood pressure $\geq 130 \mathrm{mmHg}$ or diastolic blood pressure $\geq 85 \mathrm{mmHg}$ or treatment of previously diagnosed hypertension

5. Fasting glucose $\geq 5.5 \mathrm{mmol} / \mathrm{L}(100 \mathrm{mg} / \mathrm{dL})$ or previously diagnosed diabetes.

\section{Data Collection}

The approval from institutional ethics committee was taken. All the study subjects were explained about the study procedure and informed consent was taken. Patient's sociodemographic data was collected.

BMI and anthropometric measurements like waist circumference, BMI was taken on admission and then lipid profile was done. With the use of predesigned study Performa, the relevant history and physical examination was recorded.

\section{Anthropometric Measurements and Body Composition Analysis}

Body weight was measured by using electronic weighing scale. Stature was measured by using a fixed stadiometer. Participants were made to stand against the upright surface of the stadiometer with back of the head, shoulders, buttocks, calves, and heels touching to it. Waist circumference was measured by using a measuring tape positioned between the lower rib margin and high point of the iliac crest. BMI was calculated by the formula:

BMI = weight $(\mathrm{Kg}) \div \operatorname{height}^{2}\left(\mathrm{~m}^{2}\right)$

Lean mass was calculated by using the Boer Formula:

For males:

eLBM $=0.407 \times$ weight $(\mathrm{Kg})+0.267 \times$ height $(\mathrm{cm})-19.2$

For females:

$\mathrm{eLBM}=0.252 \times$ weight $(\mathrm{Kg})+0.473 \times$ height $(\mathrm{cm})-48.3$

Then the body fat percentage (BF\%) was calculated as follows:[14]

$\mathrm{BF} \%=$ weight-lean mass $/$ weight $\times 100$

\section{Laboratory Measurements}

Lipids was measured enzymatically by using the commercially available reagents. The test was done with a blood sample, which is drawn through a needle from a vein in the arm during a fasting state. All samples were analysed for total cholesterol, triglycerides, low density lipoprotein-cholesterol (LDL-C), high density lipoprotein-cholesterol (HDL-C). HDL cholesterol was measured in the clear supernatant after precipitating the other lipoproteins with heparin and $\mathrm{MnCl}_{2}(1.3 \mathrm{~g} / \mathrm{L}$ and $0 \cdot 046$ $\mathrm{mol} / \mathrm{L}$, respectively) and removing excess $\mathrm{Mn}^{2+}$ by precipitation with $\mathrm{NaHCO}_{3} .{ }^{[14]}$

\section{Statistical Analysis}

Proportion of normal weight obesity in cardiovascular disease patient was compared with obesity in controls. Chi square test was applied over the distribution and p-value was reported. Comparison of proportion between the two groups was done using t-test.

\section{RESULTS}

\begin{tabular}{|c|c|c|c|c|c|c|}
\hline \multirow[t]{2}{*}{ Factors } & \multicolumn{2}{|c|}{ Case } & \multicolumn{2}{|c|}{ Control } & \multicolumn{2}{|c|}{ P-Value } \\
\hline & Male & Female & Male & Female & Male & Fema \\
\hline weight & $65.05 \pm 8.72$ & $56.81 \pm 3.94$ & $67.84 \pm 6.42$ & $69.16 \pm 8.28$ & 0.09 & 0.0007 \\
\hline Height & $\begin{array}{c}163.15 \pm \\
10.94\end{array}$ & $154.81 \pm 3.76$ & $172.45 \pm 7.52$ & $168.5 \pm 8.80$ & 0.00 & 0.0004 \\
\hline BMI & $24.32 \pm 0.65$ & & 51 & & 0.000 & 0. \\
\hline Lean mass & 7.22 & 37 & \pm 4.19 & 48. & 0.00 & 0.003 \\
\hline$\% \mathrm{Boc}$ & 7.23 & 35. & \pm 5.48 & 23.3 & 30.01 & 0.03 \\
\hline $\begin{array}{l}\text { Waist } \\
\text { ircumference }\end{array}$ & $e^{102}$ & & \pm 2.04 & 79 & 0.000 & 0.000 \\
\hline LDL & $\begin{array}{c}104.71 \pm \\
22.08\end{array}$ & 10 & 2.4 & $\begin{array}{c}103.66 \pm \\
20.57\end{array}$ & 0.23 & 0.52 \\
\hline HDL & $30.12 \pm 6.98$ & 33.4 & 6.03 & $45 \pm$ & 0.00 & 0.008 \\
\hline Triglyceride & $156.84 \pm 7.28$ & $\begin{array}{r}161 . \\
10\end{array}$ & $99 \pm 20.83$ & 109.6 & 0.00 & 0.00 \\
\hline choles & $\begin{array}{c}167.69 \pm \\
28.31\end{array}$ & $\begin{array}{c}177.72 \pm \\
16.93\end{array}$ & $\begin{array}{c}157.68 \pm \\
26.12\end{array}$ & $\begin{array}{c}153.66 \pm \\
15.78\end{array}$ & 0.09 & 0.01 \\
\hline 1 & $\mathrm{Fe}$ & I. & 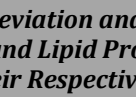 & . & & \\
\hline
\end{tabular}

\begin{tabular}{|c|c|c|}
\hline & Case & Control \\
\hline Age & $\begin{array}{l}\text { Age should be under greater } \\
\text { than } 20 \text { to less than } 60 \text { years. }\end{array}$ & $\begin{array}{l}\text { Age should be under greater than } \\
20 \text { to less than } 60 \text { years. }\end{array}$ \\
\hline Gender & $\begin{array}{l}\text { Male and female both can be } \\
\text { taken }\end{array}$ & Male and female both can be taken \\
\hline BMI & BMI less than $25 \mathrm{Kg} / \mathrm{m}^{2}$ & BMI less than $25 \mathrm{Kg} / \mathrm{m}^{2}$ \\
\hline Criteria & $\begin{array}{l}\text { Patient satisfying three } \\
\text { criteria of metabolic } \\
\text { syndrome in case }\end{array}$ & $\begin{array}{l}\text { Patient satisfying less than three } \\
\text { criteria of metabolic syndrome in } \\
\text { controls }\end{array}$ \\
\hline Disease & $\begin{array}{l}\text { Only cardiovascular disease } \\
\text { patients }\end{array}$ & $\begin{array}{c}\text { Patients of disease other than } \\
\text { cardiovascular diseases }\end{array}$ \\
\hline
\end{tabular}

In accordance of our obtained values we found that weight in female $(56.81 \pm 3.94)$, height in both male $(163.15 \pm 10.94)$ and female $(154.81 \pm 3.76)$ are significantly associated with the MONW as their P-value is less than 0.05. Whereas the resultant BMI in male (24.32 \pm 0.65$)$, lean mass in both males $(22.79 \pm 7.23)$ and females $(37.05 \pm 7.14)$ are significantly associated with the MONW. The $\%$ body fat $(22.79 \pm 7.23)$ in males, $(35.04 \pm 9.73)$ in females and waist circumference in males (102.93 \pm 1.12$)$, female $(93 \pm 0$ ) are significantly associated with the MONW. According to the obtained data on the lipid profile the Serum LDL in both the genders and cholesterol in males had the P- value of greater than 0.05 that show the both these factors are not associated with MONW thus may be not the cause of developing the Cardiovascular 
diseases in MONW subjects. But the cholesterol in female $(153.66 \pm 15.78)$ showing a significant association in MONW subjects.

Whereas the Serum HDL male $(30.12 \pm 6.98)$, female (33.45 \pm 8.34$)$ and Triglyceride male (156.84 \pm 7.28$)$, female $(161.45 \pm 10.34)$ having P-values less than 0.05 showing a strong association of both these factors in development of cardiovascular disease in MONW subjects.

\section{DISCUSSION}

Metabolically obese normal weight subjects have been described since the late 1990s.[15] MONW is significantly associated with cardio metabolic dysregulation and a high prevalence of metabolic syndrome, which is in fact, similar to the prevalence of metabolic syndrome described in overweight subjects.[16]

BMI, have a higher risk of cardio metabolic abnormalities and a higher risk of future cardiovascular disease and mortality.[7] Since fat and lean tissue discrimination is not possible by using BMI; it has limitation as a common scale of obesity. Studies have shown, Asian populations have a greater body fat percentage than Western populations for the same given BMI value.[17,18]

A report from a cross-sectional sample of 5440 participants of the National Health and Nutrition Examination Surveys 1999-2004 in the US showed: $23.5 \%$ (approximately 16.3 million adults) of normal-weight adults who were 20 years and older, were metabolically abnormal whereas $51.3 \%$ (approximately 35.9 million adults) of overweight adults and 31.7\% (approximately 19.5 million adults) of obese adults were metabolically healthy.[19] Our results suggest that a normal body mass index (BMI) alone is not a satisfactory measurement but along with it anthropometric measurements and lipid profiling may behave as a booster to the screening for the risk of cardiovascular diseases. According to our results the BMI (in males), body fat $\%$, waist circumference and triglyceride were significantly higher in MONW subjects. Whereas height, lean mass and HDL were significantly lower in MONW subjects similar to other epidemiological studies.

MONW individuals were characterised by having low lean mass and HDL despite having a normal BMI, characteristics similar to individuals with MONW was described in our study.

Our study suggest that a normal BMI alone cannot predict the cardiovascular risk but a screening for BMI with body fat $\%$, waist, triglyceride, height, lean mass, HDL is required to do the complete assessment of a person to know the risk of cardiovascular disease and significant association between MONW and cardiovascular diseases.

\section{CONCLUSIONS}

Cardio-Vascular Disease (CVD), although primarily a disease of older population, can be averted well in advance if from an early age precautions and necessary measures are taken, the most important being lifestyle modification. Treatment of CVD is not only prolonged but also expensive for patients. This study shows that Metabolic Obese Normal Weight (MONW) individuals are associated with risk factors for cardiovascular disease. It can be stated that adiposity screening in subjects with a normal BMI could better identify those who at higher risk for cardiovascular disease.

Financial or Other Competing Interests: None.

\section{REFERENCES}

[1] Reddy KS, Shah B, Varghese C, et al. Responding to the threat of chronic diseases in India. Lancet 2005;366(9498):1744-9.

[2] Joshi P, Islam S, Pais P, et al. Risk factors for early myocardial infarction in South Asians compared with individuals in other countries. JAMA 2007;297(3):286-94.

[3] Xavier D, Pais P, Devereaux PJ, et al. Treatment and outcomes of acute coronary syndromes in India (CREATE): a prospective analysis of registry data. Lancet 2008;371(9622):1435-42.

[4] Harikrishnan S, Leeder S, Huffman M, et al. A race against time: the challenge of cardiovascular disease in developing economies. 2nd edn. New Delhi, India: New Delhi Centre for Chronic Disease Control 2014.

[5] Yusuf S, Rangarajan S, Teo K, et al. Cardiovascular risk and events in 17 low-, middle-, and high-income countries. $\mathrm{N}$ Engl J Med 2014;371(9):818-27.

[6] Prabhakaran D, Yusuf S, Mehta S, et al. Two-year outcomes in patients admitted with non-ST elevation acute coronary syndrome: results of the OASIS registry 1 and 2. Indian Heart J 2005;57(3):217-25.

[7] Mendis S, Puska P, Norrving B. Global atlas on cardiovascular disease prevention and control. World Health Organization in collaboration with the World Heart Federation and the World Stroke Organization. 2011: p. 155.

[8] Patel V, Chatterji S, Chisholm D, et al. Chronic diseases and injuries in India. Lancet 2011;377(9763):413-28.

[9] Montague CT, O'Rahilly S. The perils of portliness: causes and consequences of visceral adiposity. Diabetes 2000;49(6):883-8.

[10] Foucan L, Hanley J, Deloumeaux J, et al. Body mass index (BMI) and waist circumference (WC) as screening tools for cardiovascular risk factors in Guadeloupean women. J Clin Epidemiol 2002;55(10):990-6.

[11] Koh-Banerjee P, Wang Y, Hu FB, et al. Changes in body weight and body fat distribution as risk factors for clinical diabetes in US men. Am J Epidemiol 2004;159(12):11509.

[12] Olinto MTA, Nacul LC, Gigante DP, et al. Waist circumference as a determinant of hypertension and diabetes in Brazilian women: a population-based study. Public Health Nutr 2004;7(5):629-35.

[13] Grundy SM. Metabolic syndrome scientific statement by the American Heart Association and the National Heart, Lung, and Blood Institute. Arterioscler Thromb Vasc Biol 2005;25(11):2243-4.

[14] Romero-Corral R, Somers VK, Sierra-Johnson J, et al. Normal weight obesity: a risk factor for cardiometabolic dysregulation and cardiovascular mortality. Eur Heart J 2010;31(6):737-46. 
[15] Ruderman N, Chisholm D, Pi-Sunyer X, et al. The metabolically obese, normal-weight individual revisited. Diabetes 1998;47(5):699-713.

[16] De Lorenzo A, Deurenberg P, Pietrantuono M, et al. How fat is obese? Acta Diabetol 2003;40 Suppl 1:S254-7.

[17] Deurenberg P, Yap M, van Staveren WA. Body mass index and percent body fat: a meta-analysis among different ethnic groups. Int $\mathrm{J}$ Obes Relat Metab Disord 1998;22(12):1164-71.
[18] Gallagher D, Visser M, Sepúlveda D, et al. How useful is body mass index for comparison of body fatness across age, sex, and ethnic groups? Am J Epidemiol 1996;143(3):228-39.

[19] Wildman RP, Muntner P, Reynolds K, et al. The obese without cardiometabolic risk factor clustering and the normal weight with cardiometabolic risk factor clustering: prevalence and correlates of 2 phenotypes among the US population (NHANES 1999-2004). Arch Intern Med 2008;168(15):1617-24. 